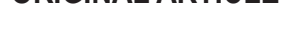

\section{Analysis of Influence Factors on Line Shape of High-speed Railway Beam-Arch Combination Bridge}

\author{
Daihai Chen, Zhenqi Xu, Yuanmiao Qiu
}

Civil Engineering School, Zhengzhou University, Zhengzhou 450001

Abstract: Taking the prestressed continuous beam-arch composite bridge on the Zheng Wan High-speed Railway as a research object, which across the South-to-North Water Transfer in Zhang Liang Town, the space finite element model of the bridge was established by Midas/Civil, the cantilever casting construction process of the main beam was simulated, and the influence of many different parameters on beam line shape of the bridge was investigate. The results show that the unbalanced weight of the hanging basket and the prestressed steel bar parameters have less influence on the beam line shape; the bulk density of concrete and the arrangement length of counterweight have a great influence on line shape, therefore, these should be considered as key control parameters during construction, the counterweight of boom beam can reduce the deformation of bridge's mid-span, it is advantageous for the Analysis of Influence Factors on Line Shape of High-speed Railway Beam-arch Combination Bridge line shape control of the bridge.

Keywords: Bridge Engineering; High-speed Railway Bridge; Continuous Beam-arch Composite Bridge; Cantilever Construction; Bridge Line Shape; Parameter Analysis

\section{Introduction}

High-speed railway requires high ride comfort, and more bridges need to be built in the line than ordinary railway. According to statistics, the proportion of bridges in the completed high 35 speed railways is about $60 \%{ }^{[1]}$. Therefore, it is especially important to control the alignment of high-speed railway bridges in their construction. At present, many scholars at home and abroad have done a lot of research on the subject of linear control during bridge construction. Ming Zhi ${ }^{[2]}$ based on the Yuanjiang Bridge on the newly-built Huai-Shao-Heng Railway, carries out parameter sensitivity analysis, establishes a linear and stress monitoring system, and carries out linear and stress monitoring on the bridge. Zhao Longjiang ${ }^{[3]}$ monitored the construction of a square prestressed concrete

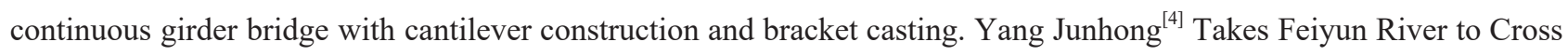
the Sea. The bridge is taken as an example, and the on-site construction control method and theoretical calculation are combined to control the bridge alignment to reach the ideal state. Han Zhixing ${ }^{[5]}$ takes a prestressed concrete continuous rigid frame bridge with a long span combination of $105 \mathrm{~m}+180 \mathrm{~m}+105 \mathrm{~m}$ as the engineering background, and carries out linear monitoring on its construction process. Teng Shuyuan ${ }^{[6]}$ takes Niujiagou Bridge as the engineering background, and adopts finite element software MIDAS/Civil pair.

The whole process of the bridge construction is analyzed and the bridge construction is guided. Zhao Shuqing ${ }^{[7]}$ takes Wushi Beijiang Bridge in Shaoguan City, Guangdong Province as the engineering background, and adopts the adaptive method to guide the construction monitoring of the bridge. Yang Yafang ${ }^{[8]}$ Combined with Xianyang Weihe Bridge on Zheng-Xi High-speed Railway. In the project, the mechanical properties and linear variation of curved bridge structures during cantilever construction are analyzed. Zhao Ruipeng ${ }^{[9]}$ By establishing a finite element model, the main influencing factors in the construction monitoring of continuous rigid frame bridge and continuous beam bridge are

Copyright (C) 2020 Daihai Chen et al.

doi:10.18282/ice.v3i1.311

This is an open-access article distributed under the terms of the Creative Commons Attribution Non-Commercial License (http://creativecommons. org/licenses/by-nc/4.0/), which permits unrestricted non-commercial use, distribution, and reproduction in any medium, provided the original work is properly cited. 
compared and studied, and a more reasonable closure procedure is proposed. Ban Xinlin ${ }^{[10]}$ carried out a study on the quality control of prestressed construction during the construction process for the $48+3 \times 80+48$ ) $\mathrm{m}$ continuous beam cantilever casting method construction of Naringchuan Bridge.

In the aspect of 50 lower bridge alignment control method, the analysis of specific multi-parameter influence on alignment of high-speed railway continuous beam-arch composite bridge is relatively few. Therefore, this paper takes the continuous beam-arch composite super-large bridge of Zheng-Wan high-speed railway Zhang Liangzhen across the South-to-North Water Transfer Project as the research object, based on the finite element model of main girder established by Midas/Civil, simulates the cantilever casting construction process of main girder, and determines the key control parameters by analyzing the influence of different parameters on the bridge alignment, which can provide reference for similar projects.

\section{Establishment of finite element model of high-speed railway continuous beam-arch composite bridge}

\subsection{Project profile}

Zheng-Wan High-Speed Railway Zhang Liangzhen Continuous Beam-Arch Composite Bridge Across the Southto-North Water Transfer Project Across the Main Canal of the Middle Route of the South-to-North Water Transfer Project is one of the controlled projects across the Henan Section of Zheng-Wan High-Speed Railway. The total length of the bridge is $309.6 \mathrm{~m}$ (including $0.8 \mathrm{~m}$ from the center line of the beam ends on both sides to the center line of the side supports respectively). The main bridge adopts the $\mathrm{m}$ prestressed concrete continuous beam-arch composite structure $(74+160+74)$. This bridge adopts the construction sequence of beam before arch, and the main beam is constructed by cantilever casting method. Each pier is provided with 3 spherical steel supports, and 0\# block is temporarily consolidated with 3 straight supports.

The diameter of 60 is $1500 \mathrm{~mm}$ concrete-filled steel tube pile, the transverse bridge direction is $0 \#$ the center of each web plate, the longitudinal bridge direction is $7 \mathrm{~m}$ from the center of the pier, the wall thickness of the steel tube pile is $12 \mathrm{~mm}$, the tube is filled with C50 concrete, the lower part stands on the bearing platform, the inner and outer walls of the bottom of the steel tube pile are welded with $\varphi 32$ steel bar to penetrate into the bearing platform $100 \mathrm{~cm}$, the inner and outer walls of the upper part are welded with $\varphi 32$ steel bar to penetrate into the $0 \#$ web plate $95 \mathrm{~cm}$, and overlap with the web bar The main girder of the bridge has a large span and most of the construction process is in an unbalanced construction state, which causes great difficulties for the linear monitoring of the bridge.

\subsection{Establishment of bridge finite element model}

This paper uses the finite element analysis software MIDAS/Civil to establish the three-dimensional finite element model of the bridge, and according to its construction process, carries on the simulation analysis to the bridge construction stage. Among them, the main girder, arch rib and pier are simulated by beam element, the suspender is discrete by tensile truss element only, and the arch foot concrete is simulated by solid element. The division of units is determined by structural characteristics, construction beam sections and calculation precision requirements. Simulation of bearings: upper and lower double joints are established at each bearing position. The upper joint is just connected with the girder joint, and the lower joint is just connected with the pier joint. General elastic connection is adopted between the upper and lower joints. The rigidity of elastic connection is determined by the bearing rigidity. Temporary

The 70 consolidation is arranged according to the actual position, and a concrete filled steel tube pile model is established, the top node of which is just connected with the main beam. There are 769 nodes and 780 elements. The full bridge finite element model is shown in Figure 1. 


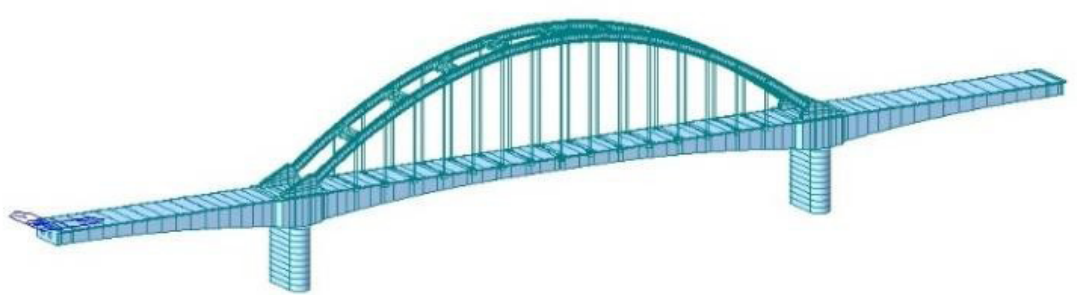

Figure 1. Three-dimensional finite element model of the whole bridge.

\section{Analysis of influence parameters of bridge alignment}

Based on the finite element model of the above-mentioned high-speed railway continuous beam-arch composite bridge, the construction process of its main beam is simulated and analyzed, and the influence rules of different parameters on the vertical deformation of the main beam in the completed state, such as the unbalanced weight of hanging basket, the unbalanced weight of suspender beam, the counterweight arrangement length of unbalanced beam section, the prestressed steel beam parameters and the concrete bulk density, are discussed.

\subsection{Hanging basket unbalanced weight}

The mid-span of the 80 girder spans the main canal of the South-to-North Water Transfer Project. In order to prevent debris such as construction garbage and sewage from falling into the main canal of the South-to-North Water Transfer Project, bottom protection and side protection must be set on the hanging basket at the mid-span side, resulting in inconsistent weight of the hanging baskets at both sides of the single T structure. In order to analyze the influence of unbalanced weight of hanging basket on main girder, two working conditions are considered: working condition 1-no protective weight; Working condition 2-add protection weight, hanging basket protection weight is 11.9 t. The difference value of the vertical deformation of the main girder (the deformation value after adding protective weight minus the deformation value without protective weight) is obtained as shown in Figure 2. As the structure is symmetrical, the analysis result is half of that, the same below.

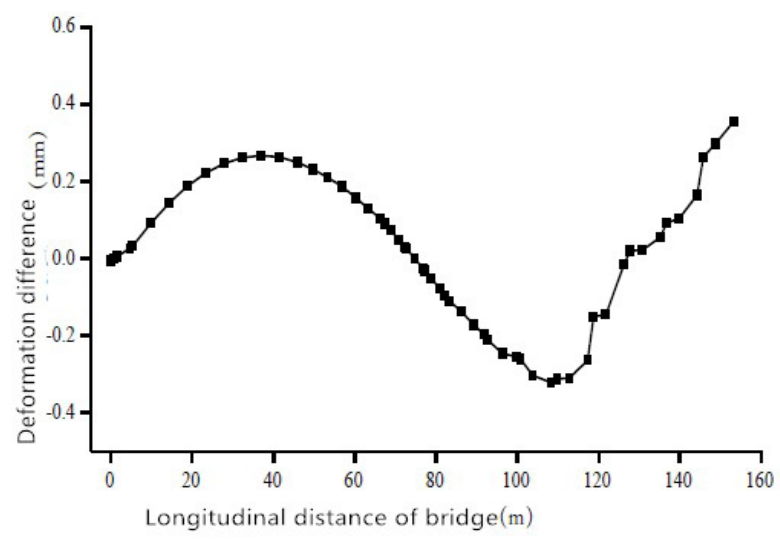

Figure 2. The effect of unbalanced weight on the bridge into the linear shape of the bridge.

As can be seen from Figure 2, when the protective weight is increased, the maximum increment of side span deformation is about $0.3 \mathrm{~mm}$, the maximum increment of mid-span deformation is about 0.4 mm and the maximum decrement of mid-span deformation is about $0.3 \mathrm{~mm}$ after the main beam is closed. The deformation change value of the completed bridge is small, which indicates the rigidity of the main girder.

\subsection{Unbalanced weight of boom beam}

In order to analyze the change of the vertical deformation of the main girder before and after the counterweight is applied to the side span of the main girder, a counterweight equal to the weight of the suspender beam is applied to the corresponding beam section position of the side span, and the vertical deformation value of the main girder after closure is calculated. The vertical deformation of the bridge before and after the counterweight is applied after the main beam is closed is shown in Figure 3. 


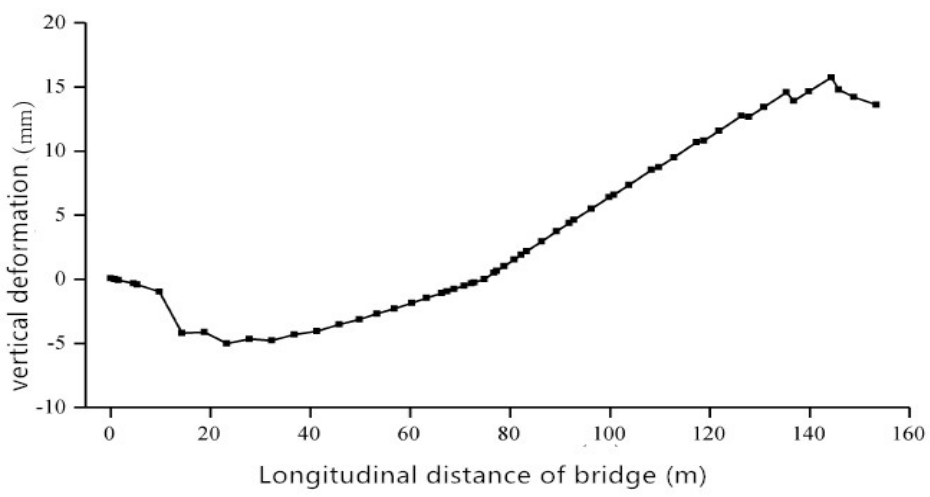

Figure 3. Influence of unbalanced weight of boom beam on linear shape of main beam.

As can be seen from Figure 3, when counterweight is applied to the side span of the main beam, the maximum deformation increment of the rear span of the main beam is about $5 \mathrm{~mm}$ and the maximum deformation reduction of the middle span is about $15 \mathrm{~mm}$. This shows that the application of boom beam counterweight during construction can reduce the mid-span deformation of the main beam and is beneficial to the linear control.

\subsection{Balance weight arrangement length of unbalanced beam section}

According to the span arrangement of the bridge, the 16 to 17 \# blocks of the mid-span are asymmetric construction beam sections. Before the construction of the unbalanced beam section of the mid-span a counterweight must be applied to the beam end of the side span, and the total weight on one side is $345 \mathrm{t}$. Due to the large counterweight, different counterweight arrangement lengths will affect the beam line shape. In the calculation process, the arrangement length of the counterweight applied to the unbalanced beam section at the side span is respectively taken as $5 \mathrm{~m}, 10 \mathrm{~m}, 15 \mathrm{~m}$ and $20 \mathrm{~m}$, and the deformation value of the main beam after closing is obtained. The difference in vertical deformation between the arrangement lengths of $10 \mathrm{~m}, 15 \mathrm{~m}$ and $20 \mathrm{~m}$ and the arrangement length of $5 \mathrm{~m}$ is shown in Figure 4.

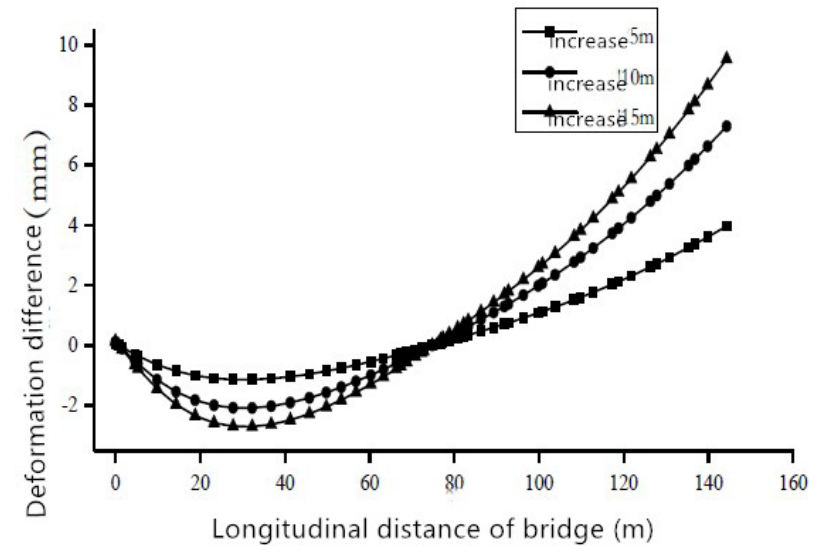

Figure 4. Influence of the distribution length of the weight on the linear shape of the main beam.

As can be seen from Figure 4, the arrangement length is increased to make the girder edge span downward and the middle span upward. When the arrangement length of the counterweight increases to $20 \mathrm{~m}$, the maximum deformation of the side span increases by $2.1 \mathrm{~mm}$, accounting for $6 \%$ of the deformation (the arrangement length is $5 \mathrm{~m}$ ), and the maximum upward warping of the middle span is $9.2 \mathrm{~mm}$, accounting for $9 \%$ of the deformation. The arrangement length of side span counterweight has great influence on the alignment of the main beam after it is closed. In the actual working process, the length of counterweight arrangement can be appropriately increased to reduce the degree of downwarping of the midspan bridge.

\section{Conclusion}

In this paper, the influence law of different parameters on the linearity of high-speed railway beam-arch composite bridge is given. The following main conclusions are drawn. 
(1). Due to the unbalanced weight of the hanging basket, the maximum increment of the deformation value of the side span is about $0.3 \mathrm{~mm}$ and the deformation value of the middle span after the main beam is closed. The maximum increment is about $0.4 \mathrm{~mm}$, the maximum reduction of mid-span deformation value is about $0.3 \mathrm{~mm}$, and the overall bridge deformation change value is small. It is said that the rigidity of the main beam is large and the weight of hanging basket protection has little influence on the alignment of the main beam.

(2). The maximum increment of the back span deformation of the main beam closure caused by the unbalanced weight of the boom beam is about $5 \mathrm{~mm}$, the maximum reduction of the mid-span deformation is about $15 \mathrm{~mm}$, and the reduction of the mid-span deformation is relatively large. The application of boom beam counterweight during construction can reduce the mid-span deformation of the main beam, which is favorable for line shape control.

(3). For the counterweight of unbalanced beam section, increasing the arrangement length will make the main beam edge span down and the middle span up and up. When the arrangement length of the counterweight increases to $20 \mathrm{~m}$, the maximum deformation of the side span increases by $2.1 \mathrm{~mm}$, accounting for $6 \%$ of the deformation (the arrangement length is $5 \mathrm{~m}$ ), the maximum upward warping of the middle span is $9.2 \mathrm{~mm}$, accounting for $9 \%$ of the deformation. The arrangement length of the counterweight has a great influence on the alignment of the main beam after it is closed. In practical engineering, the length of counterweight arrangement can be appropriately increased to reduce the degree of deflection of the mid-span bridge.

(4). Compared with the side span, the prestressed parameters have a greater influence on the vertical deformation of the main beam of the middle span after closure. When the pipeline friction coefficient is reduced by $20 \%$, the maximum deformation increment in the girder span is $1.5 \mathrm{~mm}$, accounting for $1.5 \%$ of the reference deformation (deformation according to design parameter value) at this place. When the pipeline deviation coefficient is reduced by $20 \%$, the maximum deformation increment in the girder span is $3.5 \mathrm{~mm}$, accounting for $3.6 \%$ of the original deformation at this place. This shows that the prestressed parameters have little influence on the bridge alignment.

(5). When the bulk density of concrete increases by $5 \%$, the maximum increment of the side span alignment is $5 \mathrm{~mm}$, accounting for $16 \%$ of the benchmark deformation at this place, and the maximum increment of the mid-span alignment is $19 \mathrm{~mm}$, accounting for $18 \%$ of the benchmark deformation at this place, which indicates that the bulk density of concrete has a greater impact on the alignment of the main girder after closure. In engineering practice, working procedures such as concrete formwork supporting and vibrating should be strictly controlled to ensure that the bulk density of concrete has no large deviation from the design value and that the finished bridge alignment is close to the estimated value.

\section{References}

1. Shang Shunbang, Chen Fenglan. Development of China's High-speed Railway Bridge Construction [J]. Value Engineering, 2013(19):87-88.

2. Xie Mingzhi, Zhang Tao, Yang Yongqing, Zhang Keyue, Chen Minghuan. Study on Construction Monitoring and Control System of Long-span Continuous Beam Bridge on Fast Railway [J]. Railway Standard Design, 2017,61(12):59-64.

3. Zhao Longjiang, Wang Haiyan, Cao Shusheng. Construction Control of Long Span Prestressed Concrete Continuous Girder Bridge [J]. Railway Architecture, 2011(9):24-26.

4. YANG Jun-hong, Shen Wei, ZHANG Ya-hai. Research on Line Control Technology for Cantilever Construction of Long-span Cable-stayed Bridge [J]. Highway Traffic Science and Technology, 2018,35 (Add): 115-119.

5. Han Zhixing, $\mathrm{Xu}$ Anhua. Linear analysis of long-span continuous rigid frame bridge construction monitoring [J]. Construction Technology, 2017,46 (Add): 926-929.

6. Teng Shuyuan. Linear Control of High Pier and Long Span Continuous Rigid Frame Bridge Construction in Nanshan District of Yunnan [J]. Railway Construction, 2018,58(4):37-40.

7. Zhao Shuqing, Yu Xinbo, Shen Hongtao. Application of Adaptive Control Method in Construction Monitoring of Long-Span PC Cable-Stayed Bridge [J]. Highway, 2017,62(2):170-174. [8] Yang Ya. Research on Monitoring Technology for Cantilever Construction of Prestressed Concrete Continuous Curved Girder Bridge [J]. Railway Architecture, 2016(2):31-35+42. 
8. Zhao Ruipeng. Comparative Analysis of Influencing Factors on Linear Monitoring of Continuous Rigid Frame Bridge and Continuous Beam Bridge [J]. Railway Standard Design, 2016,60(2):77-80.

9. Ban Xinlin, Ren Dan. Study on Prestressed Construction Control of $(48+3 \times 80+48)$ m Continuous Beam of Naringchuan Bridge [J]. Railway Architecture, 2015(1):36-38.

10. Wang Zhongbin. Construction Monitoring Technology for Superstructure of Wuhan Yingwuzhou Yangtze River Bridge [J]. Bridge Construction, 2018,48(1):100-105. 